\title{
Editorial
}

\section{The voice of Indonesian health scientists}

Agus Rizal A.H. Hamid

Department of Urology, Faculty of Medicine, Universitas Indonesia, Cipto Mangunkusumo Hospital, Jakarta, Indonesia

"The country has more of an oral than a written culture. The Indonesian voice in medicine and science is too quiet. It's time that voice was heard". ${ }^{1}$

One of successful story of Medical Journal of Indonesia (MJI) was the acceptance for Scopus indexing at the end of 2015. Scopus indexing was acknowledged by Indonesia Ministry of Technology and Higher Education as a journal with international reputation. Furthermore, this index does not only cover publication on 2016 onward, it also includes our entire published articles since the early publication in 1994. We should be thankful to the effort of MJI's team was lead by previous editor-in-chief, Nafrialdi MD, PhD. Because Scopus is one of database that should be used to screen articles for any systematic review or meta-analysis article, this will increase a probability of MJI's article can be tracked and cited by international scientist.

This achievement has awakened the Indonesian scientist. They have endorsed their scientific article to be published in MJI. Thus the number of submitted articles in 2016 was almost double than in 2015. Furthermore, Faculty of Medicine Universitas Indonesia (FMUI) held the $1^{\text {st }}$ Annual International Conference and Exhibition on Indonesian Medical Education and Research Institute (ICE on IMERI) in November 2016 has gathered many enthusiastic health scientists from molecular biologist, epidemiologist and clinician. There were almost 250 articles from Indonesia has been submitted to this meeting and 160 accepted articles has been prepared for a full text publication. One third of these scientists have chosen to publish their articles in MJI for academic purpose. This leads to more than 200 articles are in line for a peer review process and this number is still growing.

This high number of submitted articles needs to be organized and peer reviewed in an immediate response setting with a good quality control. A change of organizational structure in MJI is needed to overcome this situation. At the end of 2016, editorial board has agreed to expand the editorial organization. Like other well-known international journal, we have established the associate editor and assistant editor section. We have done an open recruitment and selected many enthusiastic scientists to fulfill this position. Even though these editors have a responsibility to ensure a peer review process, the decision of the article acceptance are still in the editorial board meeting. Furthermore we also expanded the number of administration staff to maintain and increase a quality of administration process i.e. the improvement of website for article processing.

Starting this volume, we invite the Indonesian government or key opinion leader to give an opinion about the recent or future of health direction and development in Indonesia. Our aim is to propagate an Indonesian health policy to international readers in our special communication section. In this edition, we are honored that Minister of Health are willing to explain one of our national programs, which called "Gerakan Masyarakat Sehat (Germas)" - Community Movement for Healthy Life. This program develop a collaboration between Ministry of Health and other ministry to overcome national health problem, which also caused by other factor i.e. education and environment. Furthermore, this program will emphasize the promotive-prevention to implement a healthy lifestyle and the family based approaches to detect early stage of disease.

We realize that there are still a lot of targets should be actualized for MJI, i.e. having an impact 
factor, to be indexed in PubMed database and increasing our publishing article or volume per year. It needs more time and effort to achieve all these targets. However, with this enthusiastic Indonesian health scientist and changes of our organizational work, I assure that we are on the right track to achieve those targets. At last, we can magnify the role of MJI as one of source for sounding the voice of Indonesian health scientist in international scope.

\section{REFERENCES}

1. Horton R. Offline: Indonesia-unravelling the mystery of a nation. Lancet. 2016;387(10021):385.

pISSN: 0853-1773 • eISSN: 2252-8083 • http://dx.doi.org/10.13181/mji.v26i1.1974 • Med J Indones. 2017;26:1-2

Corresponding author: Agus Rizal A. H. Hamid, rizalhamid.urology@gmail.com 